\title{
Analysis on Computer Data Recovery Technology and the Applications
}

\author{
Guo Xiwei \\ School of Economy and Management \\ Shenyang Aerospace University \\ Shenyang City, China
}

\begin{abstract}
With the advent of information age, computer has become a need that is more and more important for the people. Computer cannot only store a lot of data, but also increase the channels for storing data. So people store more and more data in the computer. But there will inevitably be problems for computer hard disk storing data with aging equipment, or the operating system's occasional mistakes, therefore, computer data security issues are also attracted wide attention because once the data of computer appears loopholes, at least the stored data will be lost, and even worse the entire hard disk data will have problems, which causes enormous distress and loss for the study and life of people. This problem causes computer data recovery technologies emerging, and bringing the convenience, the paper made a brief analysis of the data recovery technology and its application.
\end{abstract}

Keywords-Computer storage; Data recovery technology; Application analysis

\section{INTRODUCTION}

Computer data storage, backup and recovery technology is one of the basic technologies of computer. As computers are widely used in people's lives, more and more data is stored, and for various reasons, data loss is inevitable, and some important data is therefore not timely and professional recovered, resulting in significant losses. Then, when the data is lost unexpectedly in a computer, how to retrieve the data?

\section{ANALYSIS ON COMPUTER DATA RECOVERY}

\section{TECHNOLOGY}

\section{A. Storage of data}

To recover the data, firstly we must understand the principles of data storage. For the new hard risk, it can only be used after several steps including low-level formatting, partitioning and high-level formatting. Firstly, low-level formatting divides the hard disk track and sector and partitioning is to divide the hard disk into several regions, in order to facilitate management. Finally, high-level formatting stores the data in accordance with the provisions. Different regions connect and cooperate closely to achieve that the operating system can write and read the hard disk.

\section{B. What is the data and date recovery?}

Computer is a kind of electronic calculator for high-speed computing. To calculate, the calculator must have enough appropriate information, and the data is information forms and carriers. It is composed of various letters, number symbols combination, voice, video, graphics components. The recovery of computer data refers to a computer behavior to restore and find the damaged or lost data and make it read normally.

\section{Computer data recovery principle}

Data storage in computer is to store the data in the form of electromagnetic signals, and when the data is deleted, the computer storage section won't process data completely, and only a part is deleted, but the original data storage region has not been removed, in other words, the deleted data is stored only in a different way. Thus, to realize data recovery, you only need to modify and restore the deleted data.

\section{ANALYSIS ON THE REASONS OF LOSING COMPUTER}

\section{DATA}

\section{A. Storage disk hardware failure of storage data}

Generally, data is stored in a computer hard disk, and hard disk failures have a lot of reasons. One of them is the hard disk breakdown, which includes the hard disk heads damage, unidentified hard disk, motherboard damage, chip damage, power failure, computer crashes, garbage, etc. [1].

\section{B. Software disaster of storage hard disk}

In addition to the hardware elements, the loss of data also includes a lot of non-human software factors. Such software factors may be artificial operational errors, such as accidentally delete files or format. The reasons also include virus Trojan invasion and other malicious programs tempering, which are collectively referred to as the software failures of hard disk. When these failures occur, the computer usually cannot be opened, and the files cannot be viewed and so on.

\section{BASIC TECHNICAL ANALYSIS RELATING TO REALIZE \\ DATA RECOVERY}

There are three main technologies for data recovery: hardware technology, software technology, and the combination of hardware technology and software technology [2]. Among them, the software technology is mainly divided into two categories; the first category is to recover the data by storing data and data backup, which is mainly used for those who frequently use computers. 
The people who often use the computer need to store large amounts of data, and the facilities will store the data for backup within a certain time, but the drawback is that it cannot be real-time backup due to the backup of storing data, so data recovery may not be complete. The second category is to use anti-virus means for data recovery, there are many anti-virus software in the market, such as 360 antivirus, Rising Antivirus, etc., and the software will regularly kill virus within the computer to avoid data loss, but this data recovery is only be effective for the loss caused by virus, and it does not play much of a role on the data loss caused by other reasons [3].

The hardware technology is a kind of technology that is used when the hard disk itself cannot read the data. Such technique requires professional data recovery engineers with professional data recovery equipments, such as opening machine, DCK hard copy machines, to repair and replace faulty parts in a dust-free environment. Because this technique is easily affected by the hard disk models, and it's likely to cause damage to the hard disk data. Also because the professional data company needs to store the parts with large number of mediums, making consumers bear too much cost.This third is professional data recovery software, which combines software technology and hardware technology, using more advanced data reading, data analysis, data repair technology, to realize more and faster data recovery [4].

\section{ANALYSIS ON THE USING SITUATION OF COMPUTER}

\section{DATA RECOVERY TECHNOLOGY IN CHINA}

\section{A. Current situation of data recovery industry}

Firstly, there are a large number of data recovery companies. As more and more people are using computers to store information, information security is getting people's attention, and personal users also increase their data security requirements, so data recovery market demand will increase. The initial investment of data recovery industry doesn't requires not large, for working capital, also not too high, but because of the large demand, returns that can be obtained is relatively abundant, which prompts a lot of IT industry turning to investment.

Secondly, it's the analysis on data recovery industry classification. Professional data recovery companies can generally be divided into three categories based on different technologies: one category, the main business of them is computer maintenance and repair. Such companies are generally based on early prevention, and over a period of time, they will close to the customer positively for customer's computer maintenance, and in the maintenance process, they often encounter data recovery needs, so data recovery has become one of the company's business. Another category is domestic antivirus software vendors, which are the representatives. The companies mainly exist to prevent the Trojan virus, finding the virus and killing them. When the user's computer has problems, many users will depend on the antivirus software and attribute computer files lost as viruses. Along with this demand increasing, anti-virus software companies gradually join the data recovery service in their business. The last category is a kind of specialized professional institution emerged in data recovery in recent years. There are a lot of such talents with the expertise of data recovery; they can recover the customers' data in software, hardware and other reading equipments of magnetic media according to professional equipments in the company with professional skills and knowledge. The data recovery is professional, and the basic data recovery will not cause secondary deleting, so they are relatively reliable data recovery professional institutions currently in China.

Thirdly, the data recovery industry has a lot of hidden risks. Data recovery is a new industry of digital information age. In addition to huge business opportunities, any new things accompanies by certain risks. (1) regarding data recovery technology itself, due to the numerous reasons for data loss, data recovery companies cannot guarantee that they will recover all the data, so customers have a psychological conflict. (2) most risks in data recovery industry are caused by man, and less because of technical non-compliance, resulting in a lot of customers' data are deleted again [5].

\section{B. Application area analysis of data recovery technology}

At present, our data recovery technology is mainly used in two ways: First, the data recovery technology is used for the important lost electronic data of corporate customers and individual customers. This electronic data includes customer information, internal information and archives, and other technical means. The recovery brings great convenience for businesses and individuals to produce life. Second, the data recovery technology used in public security judiciary is used against a variety of computer crime. With the growing popularity of computers, more and more enterprises begin to use computers, so computer and network crimes become more and more. After finishing crime using computers, the criminals tend to clean up traces of their crimes, which give the investigation great difficulty, so it is important to restore the data. Data recovery process can be used for computer crime scene investigation, online survey, offline survey and a variety of applications. The data recovery can always guarantee the objectivity, and integrity of the original evidence, thereby improving the investigation of computer crime detection capability and efficiency.

\section{The problems existing in computer data recovery technologies in China}

The data recovery enterprises are mixed with various qualities and cluttered market, which is the main problem of computer data recovery technology currently. In the initial stage of data recovery industry, because of its small investment, high-profit features, many people in the IT industry saw the huge economic benefits, and thus switched into the data recovery industry. But because they did not really learned the data recovery expertise systematically, and just learned the rough knowledge from the Internet and other channels, resulting in scanty the professional knowledge, then spent a small amount of money according to their own understanding or some free download data recovery software and entered into the market for data recovery. They won customers at very low prices, thus increasing the cutthroat nature of the industry, resulting in many formal data recovery companies quit due to lacking of long-term customer support gradually. 
Also, because their technology is not in placing that cannot meet the requirements of the customers. So after long run, customers will lose confidence in this emerging industry.

\section{MARKET DEVELOPMENT DIRECTION AND FUTURE}

\section{EXPECTATIONS ANALYSIS OF DATA RECOVERY}

\section{SYSTEM}

Data recovery is an emerging industry, and at present, China has not yet relevant industry norm, therefore, the industry status quo is worrying. But data security is very important for everyone, so the data recovery market demand must be very great. With the direction of data recovery market, it can be found that data recovery is changed with the development of storage media.

1. The logical fault share in data recovery market is reducing, however the hardware failure rises. Logical fault is users' operating error, such as deleting, formatting, etc. The reason is that there is a lot free data recovery software on the Internet currently, and users can restore the data by searching such software according to the data loss reasons, so simple logic failure can be solved by the customers themselves, make it have smaller and smaller share in the recovery market.

2. The difficulty of data recovery systems is increasing. With the customer mastering more data recovery knowledge and using the data recovery software, customers can deal with simple data recovery, so they come to the data recovery companies only for professional help, therefore, the data recovery is more difficult, Secondly, the customer's cannot understand data recovery knowledge fully, we cannot learn the real reason for data loss, and they just blindly try, causing data being deleted twice, so the difficulty of data recovery also inadvertently increase. Besides, the development of computer requires hard disk production process to be improved, so a lot of areas of the hard disk are added with the protection process, which also increases the difficulty of data recovery to a certain extent.

3. Restored proportion of large-capacity hard drive is constantly increasing. With the increasing demand for data storage, hard disk storage capacity is constantly increasing, from the initial several hundred GB to the current TB capacity. The increase hard disk capacity makes the production process increase, and the code inside has changed, which increases the difficulty of data recovery. At present, due to technology research or data recovery company is still in the immature stage, so the large-capacity hard drive data recovery still has a certain degree of difficulty.

4. Smartphone platform data recovery has become a trend of data recovery. With the popularity of smartphones in China, mobile phone data recovery needs are gradually improving. These data recovery needs usually cover videos, photos and messages, and the reason for mobile phones data recovery is due to the phone system updates, which cause data loss, or because the phone hackers attack phone payment system with issuing the virus program. Since each mobile phone system constantly upgrades system security to prevent users from accessing the phone's built-in memory, so the smart phone data recovery needs the jailbreak or ROOT in order to obtain permission to access the built-in memory. Such recovery settings make smartphones data recovery difficulty increase [6].

5. The data recovery industry needs effective supervision and regulation in the future. For the user, data recovery often refers to commercial secrets, personal privacy. In this sensitive industry, China doesn't have a professional institution to supervise and regulate them at present, and companies engaged in data recovery industry does not have to get the authorization from the national secrecy authorities, which leads to a lot of data recovery companies cannot keep the customers' data confidential after recovery, even hyping the data, so the corporate trade secrets are stolen resulting in their business interests suffered a major loss. Leaked personal privacy brings a huge inconvenience for people's personal life. Even national secrets can be leaked, leading countries in dire peril. This is big problem to solve for data recovery industry.

\section{CONCLUSION}

The data recovery industry is the inevitable product of the rise of people's growing demand for data security. At present, our data recovery technology is still in the raised stage, so there must be a lot of problems. And the major domestic manufacturers and other technical staff are constantly exploring and innovating to enhance their competitiveness, while vigorously solving problems. Thus, with the data recovery technology development being ripe, data recovery will become more standardized, so that more users can enjoy more convenient and efficient data recovery service ease life and learning.

\section{REFERENCES}

[1] Li Jun, Computer Data Recovery Technology Exploration [J]. Electronic Testing, 2014.

[2] Chen Ying. Study on Computer Data Recovery Technology and Its Application [J] Enshi Vocational and Technical College: Comprehensive Edition, 2003.

[3] Shang Xinwen, Jia Hao. Analysis on the Application of Computer Data Recovery Technology in Criminal Investigation [J]. Dossiers, 2014.

[4] Wang Hao. On the Computer Data Backup and Data Recovery Techniques [J]. Science \& Technology Information, 2009.

[5] Zhao Zhenzhou on data Recovery Market And Industry Status [J]. Microcomputer Information, 2011,27 Volume 8

[6] Tao Yunsan. Clustering Analysis and Outlook on Hot Issues of Physical Education Experimental Research Field -taking 2005--2013 Domestic the Fifth Class Sports Journals Bibliometric Statistics for Example [J] Sports and Science, 2015. 